\title{
Optimization of Specific Draft Requirement and Hitch Length for an Animal Drawn Sub-Soiler: A Case of Sandy Clay Loam Soils
}

\author{
Nicodemus K. Mwonga*, Ayub N. Gitau, Joackim M. Mutua, Simon T. Mwangi \\ Department of Environmental and Biosystems Engineering, University of Nairobi, Nairobi, Kenya \\ Email: *nmkyalo@gmail.com
}

How to cite this paper: Mwonga, N.K., Gitau, A.N., Mutua, J.M. and Mwangi, S.T. (2019) Optimization of Specific Draft Requirement and Hitch Length for an Animal Drawn Sub-Soiler: A Case of Sandy Clay Loam Soils. Open Journal of Optimization, 8, 83-99.

https://doi.org/10.4236/ojop.2019.83008

Received: June 28, 2019

Accepted: September 6, 2019

Published: September 9, 2019

Copyright $\odot 2019$ by author(s) and Scientific Research Publishing Inc. This work is licensed under the Creative Commons Attribution International License (CC BY 4.0).

http://creativecommons.org/licenses/by/4.0/

(c) (i) Open Access

\begin{abstract}
This study aimed at optimizing tillage depth and hitching length for optimal draft requirement in sandy clay loam soils for animal drawn subsoiler. Field experiments were conducted to collect draft datasets using the MSI 7300 digital dynamometer communicating remotely with MSI-8000 RF data logger connected to a laptop through the serial port. To determine the numeric values of soil parameters pertinent to subsoiling, field experiments, laboratory tests and numerical analysis techniques were employed. For a specified speed, a combination of three hitch lengths of $2.5 \mathrm{~m}, 3.0 \mathrm{~m}$ and $3.5 \mathrm{~m}$ and three depths from $0 \mathrm{~cm}$ to $30 \mathrm{~cm}$ with a range of $10 \mathrm{~cm}$ interval was used. Soil bulk density was found to vary between 1.52 to $1.37 \mathrm{~g} / \mathrm{cm}^{3}$ and 1.44 to $1.67 \mathrm{~g} / \mathrm{cm}^{3}$ for Machakos and Kitui experimental plots respectively. Soil moisture content increased with an increase in depth ranging from 3.53\% to $9.94 \%$ for Machakos site and from $4.15 \%$ to $9.61 \%$ for Kitui site. Soil shear strength parameters ranged between 21.71 and $29.6 \mathrm{kPa}$ between depths of $0-20 \mathrm{~cm}$ and decreased to $28.07 \mathrm{kPa}$ for depths beyond $20 \mathrm{~cm}$ at Machakos experimental plot; while for Kitui experimental plot, it ranged between 30.02 and $39.29 \mathrm{kPa}$ between depths of $0-30 \mathrm{~cm}$. A second-order quadratic expression of the form $y$ $=a x^{2}+b x+c$ was obtained for the relationship between specific draft and depth at given hitching length as well as specific draft against hitching length at a given depth. The optimal hitching length and tillage depth for Machakos experimental plot were obtained as $2.9 \mathrm{~m}(\sim 3 \mathrm{~m})$ and $16.5 \mathrm{~cm}$ respectively. In Kitui experimental site, the optimal hitching length was obtained as $2.9 \mathrm{~m}(\sim 3$ $\mathrm{m}$ ) and the optimal tillage depth was $15.4 \mathrm{~cm}$.
\end{abstract}

\section{Keywords}

Soil Resistance, Specific Draft, Hitching Length, Subsoiling Depth, Animal Power 


\section{Introduction}

Kenya is a predominantly dry country with about $80 \%\left(467,200 \mathrm{~km}^{2}\right)$ of the total area falling under Arid and Semi-Arid Lands (ASAL). The rains are low and erratic and vary greatly both in space and time. Rainfall events are generally intense and can produce considerable runoff and soil erosion. Over the last decades, there has been a general decline in cropped land productivity. Land degradation, which includes soil compaction, diminishing plant-available moisture and reduced soil fertility has been identified as factors behind this gradual decline in agricultural productivity, which has immensely contributed to food insecurity in the county especially in the ASAL.

Intensive land preparation by animal or tractor drawn ploughs, hand hoe or and removing of crop residue by burning are the main causes of land degradation because it leaves the soil exposed to hazardous climatic conditions for instance sun, wind and rain [1]. It is important to examine land preparation practices, which will improve soil and water conservation and systematically reverse land degradation trend for increased crop yields.

Agricultural mechanization is one of the major agricultural production inputs and a catalyst for rural development. Application of agricultural mechanization technology increases power to agriculture, largely therefore enhancing the productivity of human labor. Despite agricultural mechanization being vital for agricultural production, most farming communities lack appropriate machinery and equipment to undertake their operations efficiently and effectively. Currently the use of motorized power stands at 30 percent; hand and animal draught power (ADP) at 20 percent and 50 percent respectively at the National level [2].

The relatively low level of mechanization is due to a number of challenges facing the subsector. These include: inadequate research and technology development, weak local manufacturing and distribution, and insufficient agricultural mechanization quality assurance, low level of investments in mechanization services, poor extension and technology adoption, weak institutional and legal framework. The cross-cutting issues affecting agricultural mechanization include matters related to vulnerable groups, gender and youth, negative effects of the environment, inappropriate land use and climate change.

In Kenya, a larger population resides in the rural areas, mainly in ASAL and depends on Agriculture for their livelihood. These Communities have been using Animal Draught Power (ADP) for cultivation and transportation for ages. Although there has been a significant improvement in achieving large ploughed areas, the yields have been low owing to the use of inappropriate tools that have not mobilized the soil effectively [3].

There are three main factors that influence performance of a tillage tool drawn by an animal these are soil initial conditions, tool geometry and the manner in which the tool moves [4] [5] [6]. Among these factors, only geometry of tool is in the designer's control. Initial soil condition will change from time to time and place-to-place and animal power has restricted working speed and capacity to pull. 
Tillage tool geometry has received immense emphasis in the past years; this is considering that an ideal tool should perform satisfactorily over a wide range of initial soil conditions and tillage depths [4]. Considering the importance of sub-soiling in view of its environmental effect on reducing soil compaction, enhancing water storage and reducing soil and water erosion and seemingly declining availability of draft animal power, it is imperative to evaluate the performance of an animal drawn sub-soiler at different hitch length and depths of tillage.

Although agricultural mechanization has increased at a rate of $1.0 \%$ to $1.5 \%$ per year in the developing countries such as Kenya, draft animals still remain a major source of farm power providing nearly $50 \%$ of the agricultural power [7]. Animals utilized as a source of traction, include oxen and donkeys in the study area while in other parts of the world horses, mules, buffalo and cattle are used. In addition to utilization as a source of power, these same animals provide fuel, wool, hair, offspring and by-products, such as hides, horns, hooves and meat at the end of their working lives. The extent to which draft animals are employed in tillage might lead one to expect considerable information on guidelines for utilization, but this is not the case, particularly for sub-soiling which is a more recent conservation tillage technology that has not been fully explored especially in the ASAL.

Conventional tillage using oxen or tractor drawn ploughs has been perceived as the indicator of farm systems modernization in developing countries over years [8]. This has not worked well in tropics where the temperatures are high, the rainfalls are erratic and very intensive and the soils are prone to erosion. Minimum and Conservation tillage coupled with the use of appropriate tools and equipment offers a window of opportunity to convert degraded soils into productive soils and thereby improves crop yields, reduces land degradation ultimately addressing environmental conservation concerns [9] [10].

Numerous studies have concentrated on effect of depth, rake angles and speed on draft requirement while limited studies have been done on the effect of hitch length and tillage depth on draft requirement for an animal drawn equipment. This study evaluated the effect of varying the tillage depth and draft hitch length on draft power requirement for draft animals in the lower Eastern part of Kenya particularly in Kitui and upper parts of Machakos counties.

\section{Materials and Methods}

\subsection{Experimental Site}

The study was conducted in Machakos and Kitui Counties on experimental fields shown in Figure 1 and Figure 2 respectively.

\subsection{Data Collection Approach}

\subsubsection{Experimental Set-Up and Methodology}

Field and laboratory experiments were conducted to determine numerical values of soil parameters pertinent to subsoiling. Draft requirement was recorded using 
the MSI 7300 digital dynamometer attached between the equipment and the bullocks as shown in Figure 3 using hitches and steel shackles. The dynamometer remotely was communicating with a data logger MSI $8000 \mathrm{RF}$ connected to the computer capturing the draft power instantaneously.

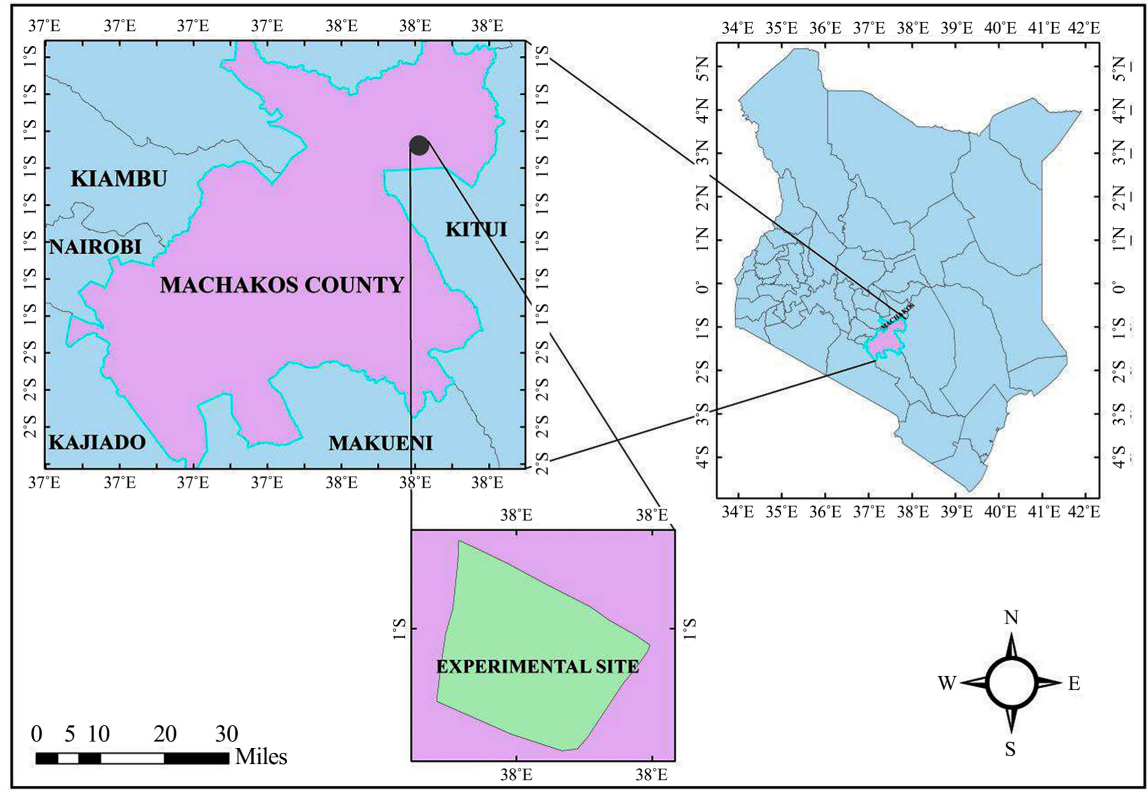

Figure 1. Machakos experimental plot.

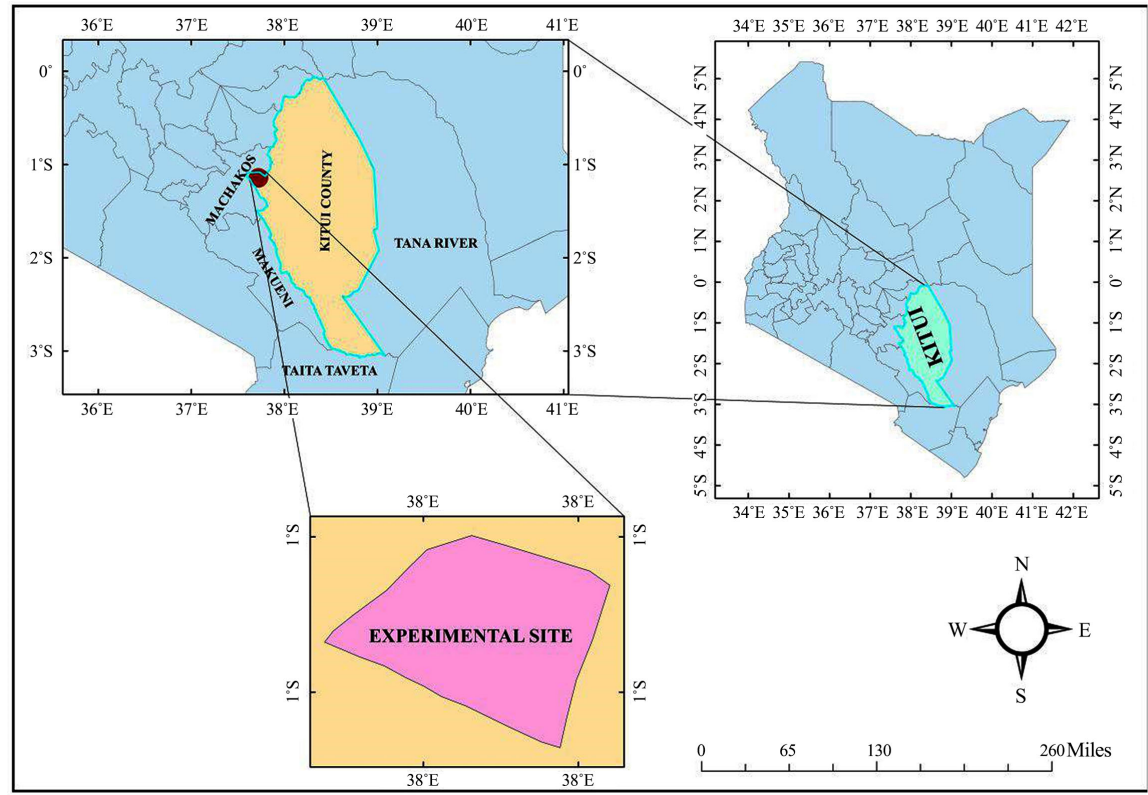

Figure 2. Kitui county experimental plot.

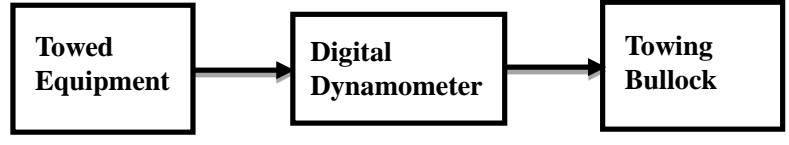

Figure 3. The experimental set-up. 
The sub-soiler was attached to the frame as shown in Figure 4.

At the start of the experiments, a run of the system described in Figure 3 was done with the tillage tine disengaged to establish the rolling resistance of the towed equipment. Draft for each hitch length and depth of sub-soiling combination was determined by subtracting rolling resistance from the draft obtained when the tool is engaged. A sample of the data obtained is represented in Table 1.

\subsubsection{Experimental Design and Treatments}

The parameters investigated for the draft measurement included width and depth of tillage. For a specified speed, three hitch lengths of $2.5 \mathrm{~m}, 3.0 \mathrm{~m}$ and 3.5 $m$ for each depth and three depths from $0 \mathrm{~cm}$ to $30 \mathrm{~cm}$ with a range of $10 \mathrm{~cm}$ were used in combination. For each set up, three replications were performed giving a total of 27 treatments.

\subsubsection{Soil Characterization}

The soil physical and mechanical properties (soil moisture, texture, structure, bulk density, shear stress and penetration resistance) were determined during the study. Soil samples were collected randomly to depths of $30 \mathrm{~cm}$ with each test plot having at least three soil samples. The soil samples were collected using sealed plastic containers clearly labelled with reference numbers indicating the plot and the depth from which the sample was collected.

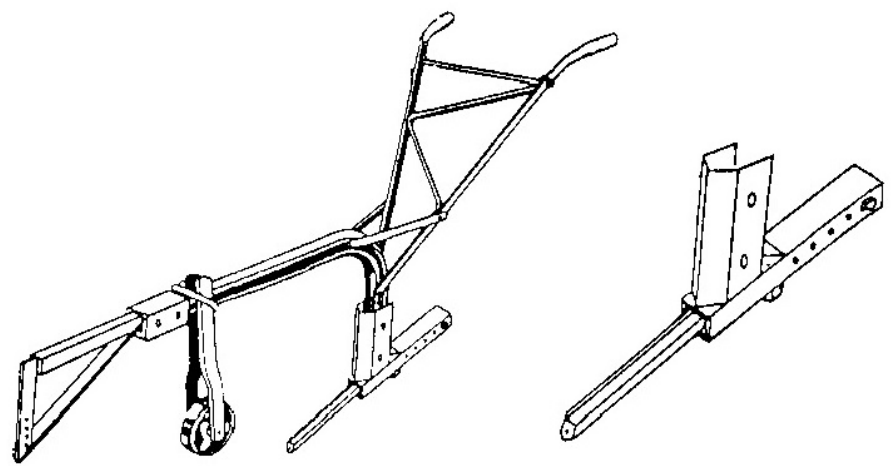

Figure 4. Subsoiler attachment [11].

Table 1. Sample Draft data $(\mathrm{kN})$ from the dynamometer.

\begin{tabular}{ccccccccc}
\hline \multicolumn{7}{c}{ Hitching length= 2.5 m } \\
\hline Plot 1 & Plot 1 & Plot 1 & Plot 2 & Plot 2 & Plot 2 & Plot 3 & Plot 3 & Plot 3 \\
\hline 1.22 & 1.32 & 1.80 & 1.48 & 1.04 & 1.78 & 0.66 & 1.46 & 1.14 \\
1.12 & 1.36 & 1.74 & 1.50 & 1.18 & 1.84 & 0.98 & 1.48 & 1.36 \\
1.10 & 1.48 & 1.78 & 1.44 & 1.26 & 1.78 & 1.06 & 1.58 & 1.40 \\
1.06 & 1.52 & 1.92 & 1.46 & 1.16 & 1.90 & 1.04 & 1.54 & 1.72 \\
1.24 & 1.36 & 1.90 & 1.20 & 1.14 & 2.22 & 0.98 & 1.50 & 2.02 \\
\hline
\end{tabular}




\subsubsection{Statistical Analysis}

Outliers were eliminated from the draft dataset obtained from the field tests using the interquartile range. The datasets were compared using statistical measures of fit particularly the coefficient of determination $\left(R^{2}\right)$ and the student $\mathrm{t}$-test.

The coefficient of determination, $R^{2}$ was computed using Equation (1)

$$
R^{2}=\frac{\mathrm{SSR}}{\mathrm{SST}}=\frac{\text { sum of squares explained by regression }}{\text { Total sum of squares }}
$$

where

$$
\begin{aligned}
\mathrm{SSR} & =\sum[\hat{y}-\bar{y}]^{2} \\
\mathrm{SST} & =\sum[y-\bar{y}]^{2}
\end{aligned}
$$

Effects of hitching length on draft power and effect of depth on draft requirement was assessed by ANOVA using the linear mixed model [12]. The protected SED mean separation procedure at $\mathrm{P} \leq 0.05$ was used to compare treatment means [13].

\section{Results and Discussion}

\subsection{Soil Characteristics}

\subsubsection{Shear Strength}

Soil shear strength, Cohesion and angle of internal friction are represented in Table 2.

There is a general increase in soil shear strength with increase in depth. At Experimental site in Machakos, the shear strength increases from 21.71 to 29.6 $\mathrm{kPa}$ from depth of $0-20 \mathrm{~cm}$ and then decreases to $28.07 \mathrm{kPa}$ between $20-30 \mathrm{~cm}$ indicating the presence of a hard pan between depth of $10-20 \mathrm{~cm}$ and the soil starts to loosen below $20 \mathrm{~cm}$.

In Kitui experimental site, the shear strength increased from a low of 30.02 $\mathrm{kPa}$ at depths of $0-10 \mathrm{~cm}$ to a high of $39.29 \mathrm{kPa}$ at depths of $20-30 \mathrm{~cm}$ (Figure 5). This was indicative of less compacted soils at the surface and presence of

\begin{tabular}{|c|c|c|c|c|}
\hline & $\begin{array}{l}\text { Depth } \\
\text { (cm) }\end{array}$ & $\begin{array}{c}\text { Cohesion } \\
\mathrm{C}(\mathrm{kPa})\end{array}$ & $\begin{array}{l}\text { Internal Angle } \\
\text { of Friction }(\varphi)\end{array}$ & $\begin{array}{c}\text { Shear Strength } \\
(\mathrm{kPa})\end{array}$ \\
\hline \multirow{3}{*}{ Machakos } & $0-10$ & 5.36 & 23.06 & 21.71 \\
\hline & $10-20$ & 7.69 & 27.00 & 29.60 \\
\hline & $20-30$ & 6.30 & 27.39 & 28.07 \\
\hline \multirow{3}{*}{ Kitui } & $0-10$ & 7.35 & 27.39 & 30.02 \\
\hline & $10-20$ & 6.43 & 29.28 & 32.86 \\
\hline & $20-30$ & 8.43 & 31.72 & 39.29 \\
\hline
\end{tabular}
hardpan as the depth increases.

Table 2. Soil shear strength for the experimental sites. 


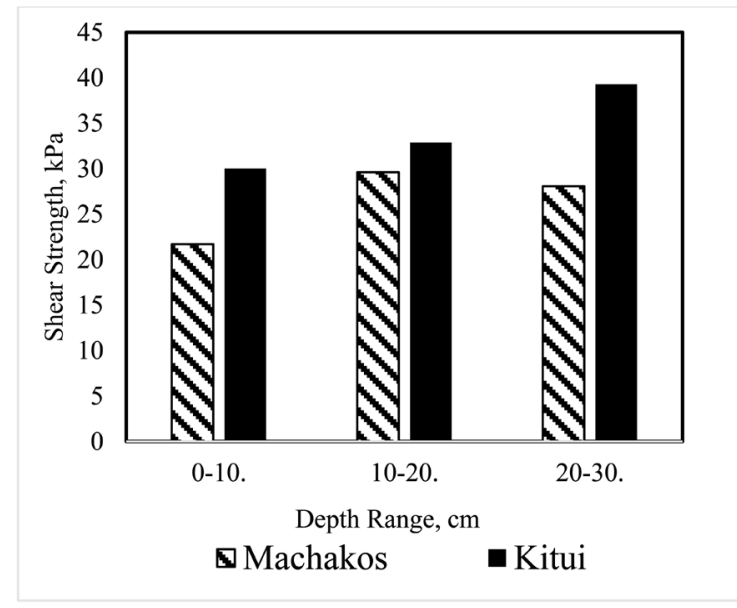

Figure 5. Soil shear strength for experimental sites.

\subsubsection{Bulk Density}

Bulk density was computed as a ratio of oven dry weight of bulk sample to the total volume of the soil core ring. For the two experimental sites, bulk density values were determined for each range of $10 \mathrm{~cm}$ depth from $0-30 \mathrm{~cm}$ and the results are shown in Table 3.

The average bulk densities for experimental plot in Machakos decreased with increase in depth from a value of 1.52 to $1.37 \mathrm{~g} / \mathrm{cm}^{3}$. However, the values for bulk densities for the experimental plot in Kitui increased with increasing depth from a value of 1.44 to a value of $1.67 \mathrm{~g} / \mathrm{cm}^{3}$ (Figure 6). The results are an indication of soil compaction/crusting on the surface for Machakos experimental field; however, these values of bulk densities are below $1.6 \mathrm{~g} / \mathrm{cm}^{3}$ beyond which there can be inhibited root growth in soil. In Kitui experimental site the compaction is below the soil surface as indicated by increasing bulk density upto $1.67 \mathrm{~g} / \mathrm{cm}^{3}$ at the depth range of $20-30 \mathrm{~cm}$. which still is within the range of $1.6 \mathrm{~g} / \mathrm{cm}^{3}$ beyond which there could be restricted root growth. Twum reported that soil bulk density is significantly influenced by soil compaction [14]. They also indicated that the bulk density of compacted soils tended to decrease with increasing depth. The dry bulk density for this soil is within the normal range of bulk densities for clay soils, which is 1.0 to $1.6 \mathrm{~g} / \mathrm{cm}^{3}$ [15]. The values for the dry bulk densities for the two experimental sites can effectively allow plant root development.

\subsubsection{Penetration Resistance}

Penetration resistance obtained at the experimental sites is presented in Table 4.

The penetration resistance of experimental field in Machakos decreased from 5.48 to $5.34 \mathrm{Mpa}$ between depths of $0-20 \mathrm{~cm}$ and increased to $5.45 \mathrm{MPa}$ between depths of $20-30 \mathrm{~cm}$. This is an indication of surface crusting and the existence of a hard pan/plough pan beyond $20 \mathrm{~cm}$. A different scenario was reported for the experimental field in Kitui. Between the depths of $0-20 \mathrm{~cm}$ penetration resistance increased from 5.35 to $5.71 \mathrm{MPa}$ indicating presence of a hardpan between depths of $10-20 \mathrm{~cm}$ as represented in Figure 7. 


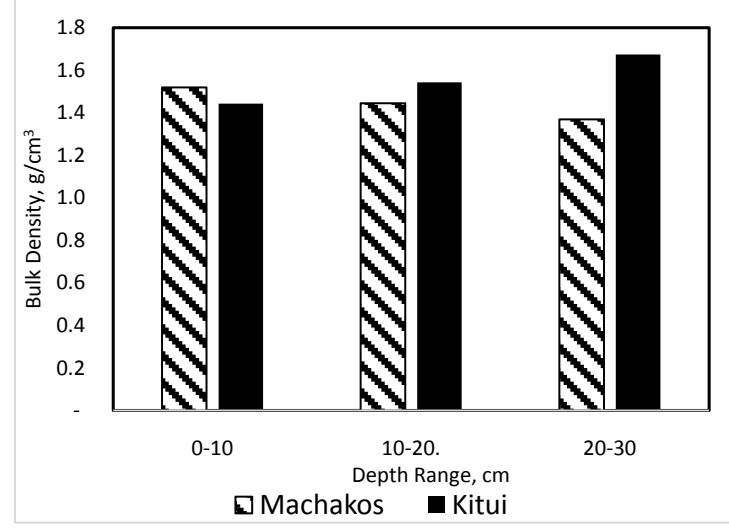

Figure 6. Soil bulk density for Experimental Sites.

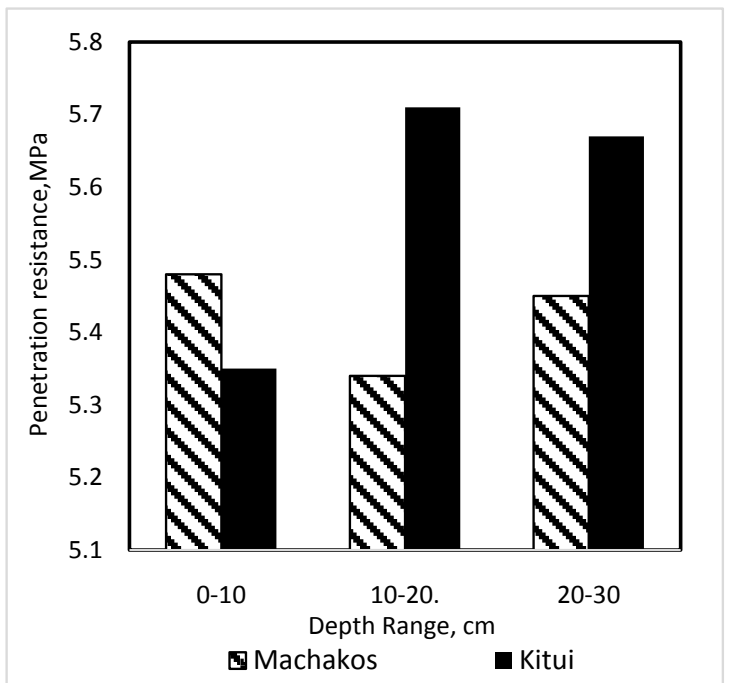

Figure 7. Soil penetration resistance for Experimental Sites.

Table 3. Bulk density results for the experimental sites.

\begin{tabular}{ccccccc}
\hline \multicolumn{7}{c}{ Bulk Density $\left(\mathrm{g} / \mathrm{cm}^{3}\right)$} \\
\hline Depth (cm) & \multicolumn{2}{c}{$0-10$} & \multicolumn{2}{c}{$10-20$} & \multicolumn{2}{c}{$20-30$} \\
\hline Plot & Machakos & Kitui & Machakos & Kitui & Machakos & Kitui \\
\hline 1 & 1.53 & 1.30 & 1.53 & 1.53 & 1.48 & 1.59 \\
2 & 1.57 & 1.38 & 1.45 & 1.62 & 1.40 & 1.86 \\
3 & 1.48 & 1.45 & 1.52 & 1.71 & 1.46 & 1.87 \\
4 & 1.58 & 1.40 & 1.32 & 1.50 & 1.25 & 1.48 \\
5 & 1.49 & 1.54 & 1.49 & 1.51 & 1.46 & 1.81 \\
6 & 1.51 & 1.41 & 1.46 & 1.63 & 1.27 & 1.82 \\
7 & 1.53 & 1.61 & 1.52 & 1.48 & 1.33 & 1.58 \\
8 & 1.56 & 1.42 & 1.42 & 1.49 & 1.40 & 1.50 \\
9 & 1.44 & 1.47 & 1.30 & 1.41 & 1.28 & 1.55 \\
Average & 1.52 & 1.44 & 1.45 & 1.54 & 1.37 & 1.67 \\
\hline
\end{tabular}


Table 4. Penetration resistance data for the experimental sites.

\begin{tabular}{|c|c|c|c|c|c|c|}
\hline \multicolumn{7}{|c|}{ Penetration Resistance (MPa) } \\
\hline \multirow[t]{2}{*}{ Depth (cm) } & \multicolumn{2}{|c|}{$0-10$} & \multicolumn{2}{|c|}{$10-20$} & \multicolumn{2}{|c|}{$20-30$} \\
\hline & Machakos & Kitui & Machakos & Kitui & Machakos & Kitui \\
\hline 1 & 5.29 & 5.34 & 5.45 & 5.47 & 4.68 & 5.73 \\
\hline 2 & 5.75 & 5.82 & 5.47 & 5.84 & 5.67 & 5.70 \\
\hline 3 & 5.81 & 5.48 & 5.77 & 5.61 & 5.61 & 5.82 \\
\hline 4 & 5.46 & 5.46 & 4.85 & 5.68 & 5.55 & 5.82 \\
\hline 5 & 5.62 & 4.81 & 5.50 & 5.63 & 5.69 & 5.85 \\
\hline 6 & 5.62 & 5.70 & 5.50 & 5.79 & 5.69 & 5.80 \\
\hline 7 & 5.34 & 5.49 & 5.39 & 5.79 & 5.65 & 4.98 \\
\hline 8 & 5.59 & 5.08 & 5.17 & 5.86 & 4.90 & 5.69 \\
\hline 9 & 4.87 & 5.05 & 5.03 & 5.69 & 5.63 & 5.67 \\
\hline Average & 5.48 & 5.35 & 5.34 & 5.71 & 5.45 & 5.67 \\
\hline
\end{tabular}

Several researchers have reported an increase in penetration resistance with tillage depth under different tillage implements [16] [17]. However, [18] [19] reported that for penetration resistance beyond $3 \mathrm{MPa}$, plant root growth is considered slow. It is therefore evident that for both Machakos and Kitui experimental sites, the penetration resistance values are beyond this limit for the studied depth of $0-30 \mathrm{~cm}$ and therefore at the two experimental sites it is recommended that ploughing could be done after the rains when the ground is wet and the hard pan is softened. Further ripping is recommended using specialized tillage implements like chisel ploughs to break the plough pan.

\subsubsection{Moisture Content}

Percentage moisture content increased with an increase in depth between the ranges $0-30 \mathrm{~cm}$. for Kitui and Machakos experimental fields (Table 5).

For Machakos experimental site, the moisture content increased from 3.53\% at a depth of $0-10 \mathrm{~cm}$, to $7.63 \%$ at a depth of $10-20 \mathrm{~cm}$ and to $9.94 \%$ at depths of $20-30 \mathrm{~cm}$. On the other hand, the moisture content increased from $4.15 \%$ at a depth of $0-10 \mathrm{~cm}$, to $6.85 \%$ at a depth of $10-20 \mathrm{~cm}$ and to $9.61 \%$ at depths of $20-30 \mathrm{~cm}$ for Kitui experimental site (Figure 8). This was indicative of loose soil and existence of more voids at the depths of $20-30 \mathrm{~cm}$ at the two experimental sites.

According to [20] soil columns tend to be drier at the top due to evaporation from the surface.

\subsubsection{Effect of Depth on Specific Draft}

Figure 9 and Figure 10 represent the relationship between specific draft and tillage depth at given hitching length for Machakos and Kitui experimental sites respectively. In all the experimental sites, a hitch length range of 2.5 to $3.5 \mathrm{~m}$ was used. These lengths were sufficient and long enough to reduce interference between the animals and the implements during handling. Further short hitch 
lengths less than $2.5 \mathrm{~m}$ will have limited the penetration of the implement and defeat the purpose of the experiment.

Table 5. Moisture data for the experimental sites.

\begin{tabular}{ccccccc}
\hline Plot & \multicolumn{2}{c}{ 0 - 10 } & \multicolumn{2}{c}{$10-20$} & \multicolumn{2}{c}{$20-30$} \\
\hline 1 & Machakos & Kitui & Machakos & Kitui & Machakos & Kitui \\
\hline 2 & 1.79 & 8.89 & 2.92 & 4.43 & 3.61 & 10.71 \\
3 & 3.43 & 3.00 & 7.28 & 7.76 & 9.63 & 9.54 \\
4 & 5.28 & 4.28 & 6.90 & 8.26 & 8.34 & 15.26 \\
5 & 2.76 & 4.86 & 9.48 & 8.40 & 12.21 & 10.41 \\
6 & 2.26 & 2.86 & 7.52 & 6.42 & 8.93 & 6.95 \\
7 & 4.86 & 3.40 & 8.59 & 7.95 & 10.05 & 9.82 \\
8 & 3.63 & 4.07 & 7.94 & 6.46 & 10.91 & 7.52 \\
9 & 3.31 & 2.43 & 7.70 & 3.32 & 14.14 & 5.00 \\
Average & 4.51 & 3.58 & 10.34 & 8.66 & 11.65 & 11.31 \\
\hline
\end{tabular}

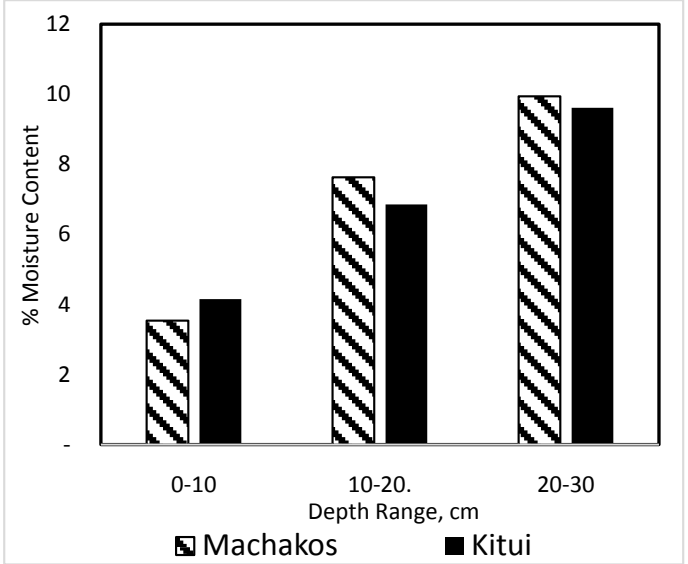

Figure 8. Percentage soil moisture for experimental site.

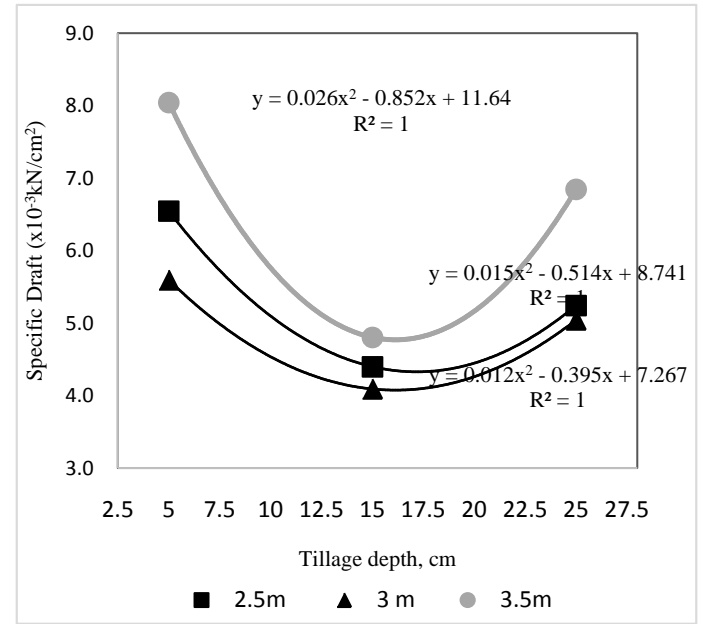

Figure 9. Specific draft against tillage depth at different hitching length for Machakos experimental site. 


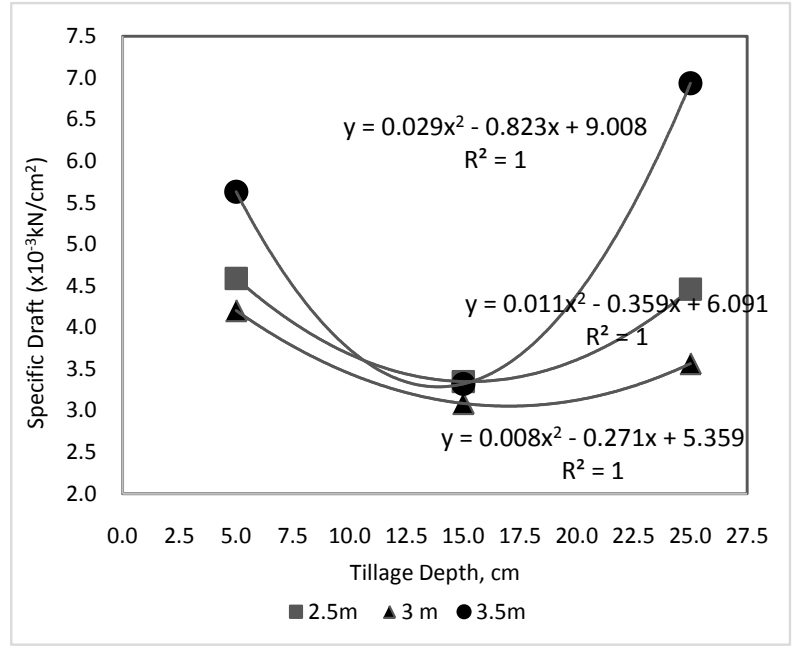

Figure 10. Specific draft against tillage depth at different hitching length for Kitui experimental site.

The results at Machakos experimental field indicated that the relationship between specific draft and tillage depth at different hitching length is a second-order quadratic equation of the form; $y=a x^{2}-b x+c$ with the coefficient of determination $\left(R^{2}\right)$ of 1 .

where,

$$
\begin{aligned}
& y=\text { specific draft, } \mathrm{kN} / \mathrm{cm}^{2} \\
& a \& b=\text { scalar quantities } \\
& x=\text { tillage depth } \\
& c=y \text {-intercept }
\end{aligned}
$$

The optimum tillage depth is given as $x$ when the gradient of the curve $y=a x^{2}$ $-b x+c$ is zero.

Similarly, for Kitui Experimental site.

The results at Kitui experimental field indicated that the relationship between specific draft and tillage depth at different hitching length is a second-order quadratic equation of the form; $y=a x^{2}-b x+c$ with the coefficient of determination $\left(R^{2}\right)$ of 1.

The optimum tillage depth is given as $x$ when the gradient of the curve $y=a x^{2}$ $-b x+c$ is zero.

The values of optimum tillage depth and optimal energy requirement for a given hitching length are given in Table 6.

\subsubsection{Effects of Hitching Length on Draft}

Figure 11 and Figure 12 represent the relationship between specific draft and hitching length at given tillage depths for Machakos and Kitui experimental sites respectively.

The results at Kitui experimental field indicated that the relationship between specific draft and tillage depth at different hitching length is a second-order quadratic equation of the form; $y=a x^{2}-b x+c$ with the coefficient of determination $\left(R^{2}\right)$ of 1 . 


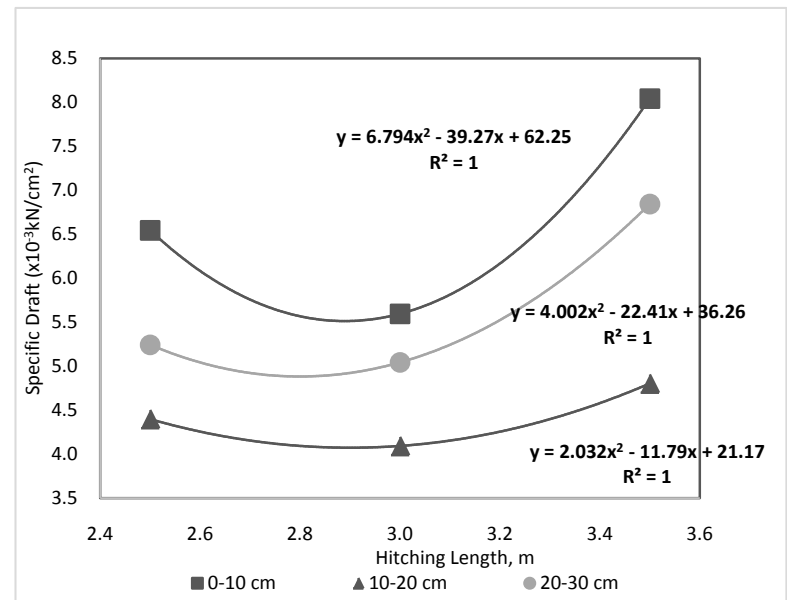

Figure 11. Specific draft against hitching length at different tillage depth for Machakos experimental site.

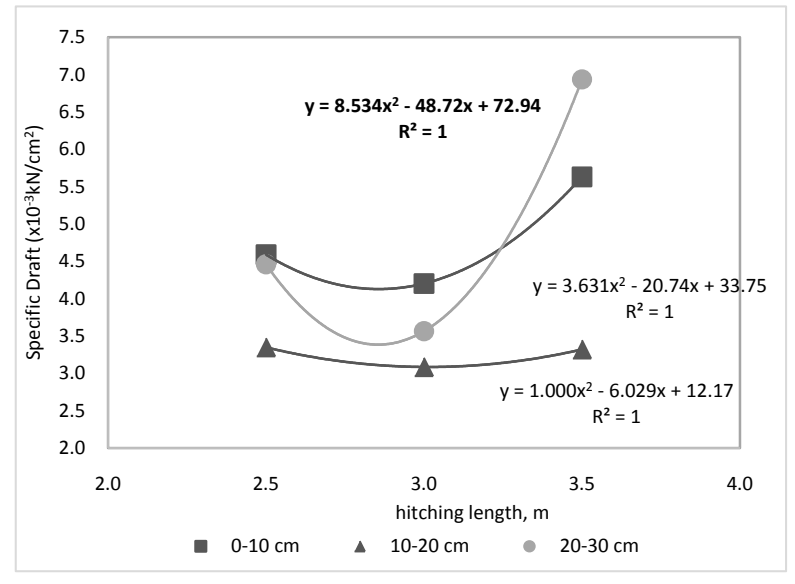

Figure 12. Specific draft against hitching length at different tillage depth for Kitui experimental site.

Table 6. Summary of optimum tillage depth and specific draft requirement at given hitching length.

\begin{tabular}{ccccccc}
\hline Hitching Length & \multicolumn{2}{c}{$2.5 \mathrm{~m}$} & \multicolumn{2}{c}{$3.0 \mathrm{~m}$} & \multicolumn{2}{c}{$3.5 \mathrm{~m}$} \\
\hline & Machakos & Kitui & Machakos & Kitui & Machakos & Kitui \\
\hline $\begin{array}{c}\text { Optimum Depth } \\
(\mathrm{cm})\end{array}$ & 17.13 & 15.22 & 16.1 & 16.97 & 16.14 & 13.91 \\
$\begin{array}{c}\text { Optimum Specific } \\
\text { Draft }\left(\mathrm{kN} / \mathrm{m}^{2}\right)\end{array}$ & 43.4 & 33.6 & 40.8 & 30.6 & 47.7 & 32.8 \\
\hline
\end{tabular}

The optimum tillage depth is given as $x$, when the gradient of the curve $y=a x^{2}$ $-b x+c$ is zero.

Similarly, for Kitui Experimental field.

It indicated that the relationship between specific draft and hitching length at different tillage depth is a second-order quadratic equation with the coefficient of determination $\left(R^{2}\right)$ of 1 . The optimum hitching length is given as $x$, when the 
gradient of the equation/curve $=a x^{2}-b x+c$ is zero.

Value of optimum hitching length and optimal energy requirement for a given tillage depth is given in Table 7.

According to [21] well-conditioned oxen are capable of working draft loads measured as tension ( $\mathrm{kg}$-force, $\mathrm{kN}$ ) equal to $10 \%-12 \%$ of their body weight throughout the day and greater loads for short periods of time. Therefore, two oxen of average weight $250 \mathrm{~kg}$ each (1 Tropical Livestock Unit) can generate a draft force of $500-600 \mathrm{~N}$ for normal pull or towing. At the experimental sites the bulls used weighed on average $250-300 \mathrm{~kg}$ each and this produced an average specific draft of $28 \mathrm{kN} / \mathrm{m}^{2}-40.7 \mathrm{kN} / \mathrm{m}^{2}$.

Average specific draft at different tillage depths and hitching length were subjected to Analysis of Variance (ANOVA). Table 8 and Table 9 for Machakos and Kitui experimental sites respectively at $95 \%$ confidence level $(P>0.05)$. The following hypotheses were tested.

Table 7. Summary of optimum hitching length and specific draft requirement at given tillage depth.

\begin{tabular}{ccccccc}
\hline Tillage Depth & \multicolumn{2}{c}{$0-10 \mathrm{~cm}$} & \multicolumn{2}{c}{$10-\mathbf{2 0} \mathrm{cm}$} & \multicolumn{2}{c}{$20-\mathbf{3 0} \mathrm{cm}$} \\
\hline & Machakos & Kitui & Machakos & Kitui & Machakos & Kitui \\
\hline $\begin{array}{c}\text { Optimal Hitching } \\
\text { Length }(\mathrm{m})\end{array}$ & 2.89 & 2.86 & 2.8 & 3.01 & 2.9 & 2.85 \\
$\begin{array}{c}\text { Optimum Specific } \\
\text { Draft }\left(\mathrm{kN} / \mathrm{m}^{2}\right)\end{array}$ & 55.1 & 41.3 & 48.8 & 30.9 & 40.7 & 33.8 \\
\hline
\end{tabular}

Table 8. Machakos experimental site specific draft summary.

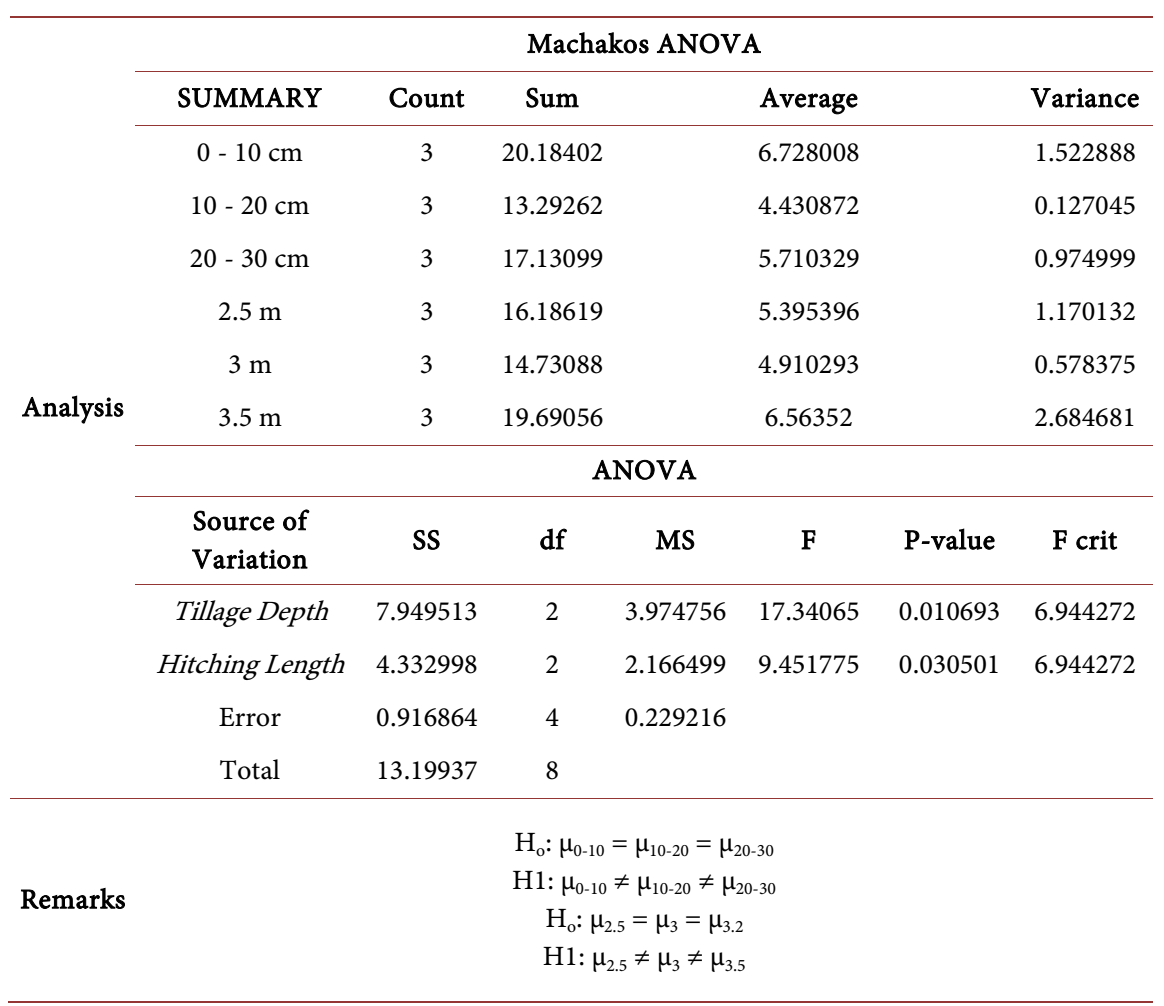


Table 9. Kitui experimental site specific draft summary.

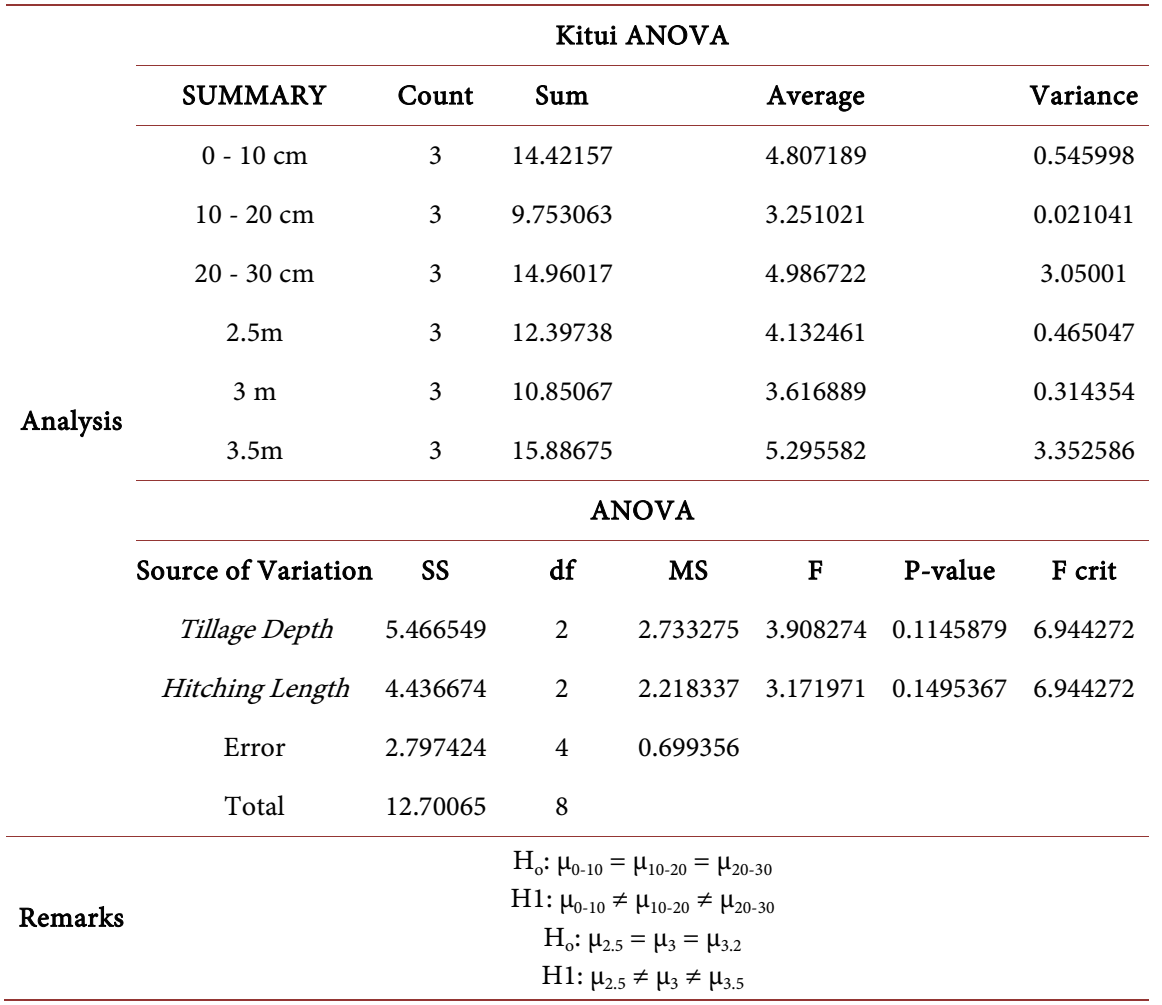

For tillage depth:

$\mathrm{H}_{\mathrm{o}}: \mu_{0-10}=\mu_{10-20}=\mu_{20-30}$

$\mathrm{H}_{1}: \mu_{0-10} \neq \mu_{10-20} \neq \mu_{20-30}$

For hitching length:

$\mathrm{H}_{\mathrm{o}}: \mu_{2.5}=\mu_{3}=\mu_{3.5}$

$\mathrm{H}_{1}: \mu_{2.5} \neq \mu_{3} \neq \mu_{3.5}$

In Table 8, the specific draft results for Machakos Experimental have significant difference across the different tillage depth as well as for different hitching lengths. The P-values obtained through ANOVA analysis are 0.010693 and 0.030501 for tillage depth and hitching length respectively, which are less than 0.05. The conclusion made therefore is that specific draft varies significantly with changing tillage depth and hitching length for Machakos experimental site.

However, a different scenario was reported for Kitui experimental site. No statistically significant difference was reported for specific draft at different tillage depths and hitching lengths. The $\mathrm{P}$ values obtained were 0.1145879 and 0.1495367 for tillage depth and hitching length respectively Table 9. These values are greater than 0.05 and therefore specific draft does not vary significantly with changing tillage depth and hitching length for Kitui experimental site.

\section{Conclusions}

The two sites Machakos and Kitui were found to have similar soils types, i.e. sandy Clay Loamy soils. At the two sites the existence of hardpan at various le- 
vels was notable. This is well-collaborated by the determined values of the bulk density, penetration resistance and shear strength at the two sites.

At the two experimental sites it was notable that beyond the depths of $20-30$ $\mathrm{cm}$ the soil was loosening, hence the existence of more voids which has been collaborated by high Percentage (\%) of moisture content. Consequently, to allow effective root development there is a need to rip or carry out sub soiling with deep penetration tillage implements to break the hardpan. Further farmers in those sites are advised to plough after the rains when the ground is wet enough to allow implement penetration.

The study established that the relationship between the specific draft, tillage depth and hitch length was a second-order quadratic equation of the form $y=$ $a x^{2}-b x+c$ with the coefficient of determination $\left(R^{2}\right)$ of 1 at the Machakos and Kitui experimental sites.

where;

$$
\begin{aligned}
& y=\text { Specific draft, } \mathrm{kN} / \mathrm{cm}^{2} \\
& a \& b=\text { scalar quantities } \\
& x=\text { tillage depth } \\
& c=y \text {-intercept }
\end{aligned}
$$

After optimization of the above model, it was found that the optimum average tillage depth was $16 \mathrm{~cm}$, at the optimum hitch length of $3 \mathrm{~m}$ when an average specific draft of $41 \mathrm{kN} / \mathrm{m}^{2}$ was applied at normal oxen operating rate in a sandy clay loam soils using an animal drawn sub-soiler. Analysis of variance (ANOVA) was carried for the results of Specific draft hitch length and tillage depth for the two experimental sites. The analysis established that specific draft varies significantly with changing tillage depth and hitching length for Machakos experimental site while for Kitui there was no significant difference and this is attributed to the shear strength characteristics.

Based on this study is can be concluded that the optimum hitching length when using oxen drawn tillage implements is $3.0 \mathrm{~m}$ which can give an optimum furrow depth of $16 \mathrm{~cm}$. This depth is sufficient enough to allow root growth for most of the crops grown in the ASAL regions.

\section{Acknowledgements}

The authors are grateful to the Department of Environmental and Biosystems Engineering, University of Nairobi, for availing research facilities and supportive staff members.

\section{Conflicts of Interest}

The authors declare no conflicts of interest regarding the publication of this paper.

\section{References}

[1] McCarthy, N., Lipper, L. and Branca, G. (2011) Climate-Smart Agriculture: Small- 
holder Adoption and Implications for Climate Change Adaptation and Mitigation. Mitigation of Climate Change in Agriculture Working Paper, 1-37.

[2] Kienzle, J. and Sims, B.G. (2014) Agricultural Mechanization Strategies for Sustainable Production Intensification: Concepts and Cases from (and for) Sub-Saharan Africa. FAO, Rome.

[3] Guthiga, P.M., Karugia, J.T. and Nyikal, R.A. (2007) Does Use of Draft Animal Power Increase Economic Efficiency of Smallholder Farms in Kenya? Renewable Agriculture and Food Systems, 22, 290-296. https://doi.org/10.1017/S174217050700186X

[4] Phillips, I.D., Fielke, S.L., Young, I.R. and McMillen, I.C. (1996) The Relative Roles of the Hypothalamus and Cortisol in the Control of Prolactin Gene Expression in the Anterior Pituitary of the Sheep Fetus. Journal of Neuroendocrinology, 8, 929-933. https://doi.org/10.1111/j.1365-2826.1996.tb00823.x

[5] Anon, (1992) Tools for Agriculture. Intermediate Technology Publications Ltd., London, $238 \mathrm{p}$.

[6] Brassington, T.J.M. (1987) Re-Examination of the Plough. Agricultural Engineer, 5, 53-57.

[7] Gitau, A.N. (1995) Tillage Practices and Draft Power Requirements for Soil Moisture Conservation of a Hard Setting Soil. Masters Dissertation, University of Nairobi, Nairobi.

[8] Johansen, C., Haque, M.E., Bell, R.W., Thierfelder, C. and Esdaile, R.J. (2012) Conservation Agriculture for Smallholder Rainfed Farming: Opportunities and Constraints of New Mechanized Seeding Systems. Field Crops Research, 132, 18-32. https://doi.org/10.1016/j.fcr.2011.11.026

[9] Rusinamhodzi, L., Corbeels, M., Van Wijk, M.T., Rufino, M.C., Nyamangara, J. and Giller, K.E. (2011) A Meta-Analysis of Long-Term Effects of Conservation Agriculture on Maize Grain Yield under Rain-Fed Conditions. Agronomy for Sustainable Development, 31, 657. https://doi.org/10.1007/s13593-011-0040-2

[10] Giller, K.E., Witter, E., Corbeels, M. and Tittonell, P. (2009) Conservation Agriculture and Smallholder Farming in Africa: The Heretics' View. Field Crops Research, 114, 23-24. https://doi.org/10.1016/j.fcr.2009.06.017

[11] Starkey, P. and Kaumbutho, P. (1999) Meeting the Challenges of Animal Traction: A Resource Book of the Animal Traction Network for Eastern and Southern Africa (ATNESA). Intermediate Technology Publications, London, $326 \mathrm{p}$. https://doi.org/10.3362/9781780445458

[12] Chartier, S. and Cousineau, D. (2011) Computing Mixed-Design (Split-Plot) ANOVA. Mathematica Journal, 13, 13-17. https://doi.org/10.3888/tmj.13-17

[13] Saville, D.J. and Rowarth, J.S. (2008) Statistical Measures, Hypotheses, and Tests in Applied Research. Journal of Natural Resources \& Life Sciences Education, 37, 74-82.

[14] Twum, E.K. and Nii-Annang, S. (2015) Impact of Soil Compaction on Bulk Density and Root Biomass of Quercus Petraea L. at Reclaimed Post-Lignite Mining Site in Lusatia, Germany. Applied and Environmental Soil Science, 2015, Article ID: 504603. https://doi.org/10.1155/2015/504603

[15] Chaudhari, P.R. Ahire, D.U. Ahire, V.D. Chkravarty, M. and Maity, S. (2013) Soil Bulk Density as Related to Soil Texture, Organic Matter Content and Available Total Nutrients of Coimbatore Soils. International Journal of Scientific and Research Publications, 3, 1-8. 
[16] Boydaş, M.G. and Turgut, N. (2007) Effect of Tillage Implements and Operating Speeds on Soil Physical Properties and Wheat Emergence. Turkish Journal of Agriculture and Forestry, 31, 399-412.

[17] Mwangi, S.T., Gitau, A.N. and Muchiri, G. (2018) Effect of Chisel Ploughing on Physical and Mechanical Soil Properties on a Maize Cropped Field. International Journal of Emerging Technology and Advanced Engineering, 8, 84-93.

[18] Bengough, A.G. and Mullins, C.E. (1990) Mechanical Impedance to Root Growth: A Review of Experimental Techniques and Root Growth Responses. Journal of Soil Science, 41, 341-358. https://doi.org/10.1111/j.1365-2389.1990.tb00070.x

[19] Vepraskas, M.J. (1994) Plant Response Mechanisms to Soil Compaction. In: Wilkerson, R.E., Plant Environment Interactions, M. Dekker, New York, 263-287.

[20] Gong, Y. Cao, Q. and Sun, Z. (2003) The Effects of Soil Bulk Density, Clay Content and Temperatute on Soil Water Content Measurement Using Time-Domain Reflectometry. Hydrological Processes, 17, 3601-3614.

https://doi.org/10.1002/hyp.1358

[21] Harrigan. T. and Roosenberg, R. (2002) Estimating Tillage Draft. Tillers International. 